Title: Philip Morris International: A New Year's resolution

Authors: Crawford Moodie ${ }^{1}$, David Hammond ${ }^{2}$, Linda Bauld ${ }^{1}$

\begin{abstract}
Affiliations:
${ }^{1}$ Centre for Tobacco Control Research, Institute for Social Marketing, School of Health Sciences and Sport, University of Stirling, Scotland

${ }^{2}$ School of Public Health and Health Systems, University of Waterloo, Canada
\end{abstract}

Corresponding author: Crawford Moodie, Centre for Tobacco Control Research, Institute for Social Marketing, School of Health Sciences and Sport, University of Stirling, Stirlingshire FK9 4LA. Email: c.s.moodie@stir.ac.uk, Tel: 0044 (0)1786 466456

Accepted for publication in Tobacco Control published by BMJ publishing: https://doi.org/10.1136/tobaccocontrol-2018-054250 


\section{Philip Morris International: A New Year's resolution}

In January 2018, Philip Morris International (PMI) placed ads in UK newspapers explaining that their New Year's resolution was 'to stop selling cigarettes in the UK', see Figure $1 .{ }^{1}$ To help achieve this goal, the PMI ads refer to four commitments for 2018:

1) Launch a website and campaign to provide smokers with information on quitting and on alternatives to cigarettes;

2) Offer to support Local Authority cessation services where smoking rates are highest;

3) Seek Government approval to insert, directly into our cigarette packs, information on quitting and on switching;

4) Expand the availability of new, alternative products in the UK.

Figure 1: PMI advert in the UK
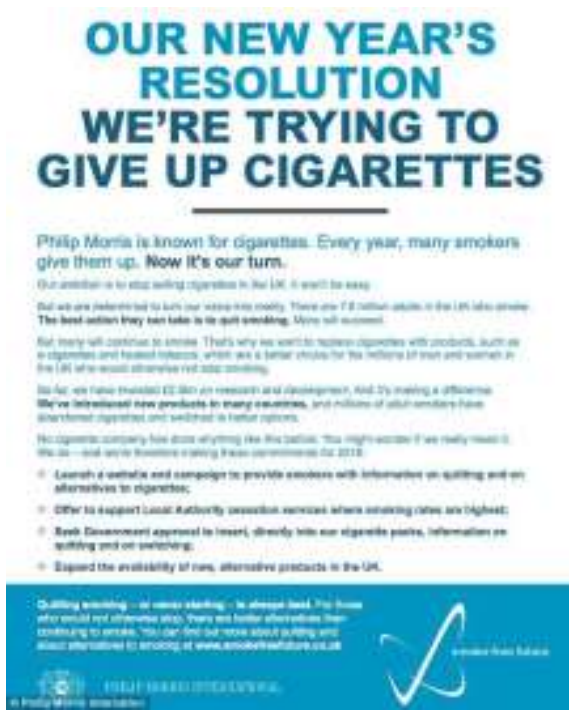

While the second commitment is contrary to Article 5.3 obligations of the WHO FCTC, ${ }^{2}$ and the third prohibited by the Standardised Packaging of Tobacco Products Regulations 2015, ${ }^{3}$ 
the latter, at least, could be amended by the UK government. The relevant text, 'No insert or additional material may be attached to or included with the packaging of a unit packet or container packet of cigarettes', could be revised with the addition of 'unless specified by Government (e.g. to educate consumers about the benefits of quitting or to promote selfefficacy to quit)'. What is apparent for all four commitments, however, is the potential that each brings for PMI to promote their alternative, non-combustible, nicotine containing products.

There may be myriad reasons why PMI chose the UK as a testing ground for this type of campaign, but the evolving nicotine market is likely reason enough. With respect to combustible products, the outlook is bleak for PMI. Smoking prevalence is at a record low in the UK, with cigarette sales falling year-on-year and volume recovery unrealistic. ${ }^{4}$ In addition, PMI's share of the cigarette market fell to $8.1 \%$ in 2016 and their most profitable brand (Marlboro), which constitutes most of this market share, has declined steadily since at least $2012 .{ }^{4}$ Furthermore, the long-term decline of the premium cigarette sector, where Marlboro is positioned, looks set to continue now that standardised packaging has been fully implemented, as was found in Australia after standardised packaging was introduced in 2012. ${ }^{5}$ That the UK is one of the largest global markets for rolling tobacco ${ }^{6}$ provides little solace for PMI, given that the three other leading tobacco companies (Imperial Brands, Japan Tobacco International, British American Tobacco) have a stranglehold on this sector in the UK.

More promising for PMI is the broad acceptance of alternative nicotine-containing products in the UK, where the government has endorsed e-cigarettes for smoking cessation. ${ }^{7}$ PMI's IQOS is currently the only heat-not-burn product on sale in the UK, having been available since November 2016. As such, PMI is well-placed to seize what may be a highly profitable opportunity if the UK government allows them to follow through on their four New 
Year's commitments. Encouraging consumers to use IQOS - whether online, via cessation services or through product packaging - would give PMI a strong competitive advantage in the UK, while simultaneously bolstering their credentials as responsible corporate citizens. In this context, their 'vision' appears driven by a financial imperative rather than a genuine desire to protect public health. If PMI were serious about stopping selling cigarettes in the UK they could have provided a clear timeline for doing so. If they are serious about eliminating smoking worldwide, ${ }^{8}$ then why do they continue to promote their combustible products $^{9}$ and litigate against evidence-based tobacco control policy. It may be a different year, a different product and a different tactic, but the goal appears to remain the same.

Concomitant with these developments in the UK, PMI have been promoting IQOS via the packaging of some of their cigarette brands in Canada (see Figure 2). PMI have a greater market share of cigarettes in Canada than in the UK (33.5\% in 2012), ${ }^{10}$ but Canada is equally hostile towards combustible tobacco and there has been a long-term decline in smoking prevalence and sales (and the premium sector). This looks likely to continue as standardised packaging and a more permissive regulatory framework for e-cigarettes are in the final legislative stages. These promotional packs in Canada suggest that PMI would use inserts in the UK to promote IQOS.

Figure 2: PMI packs in Canada promoting IQOS 


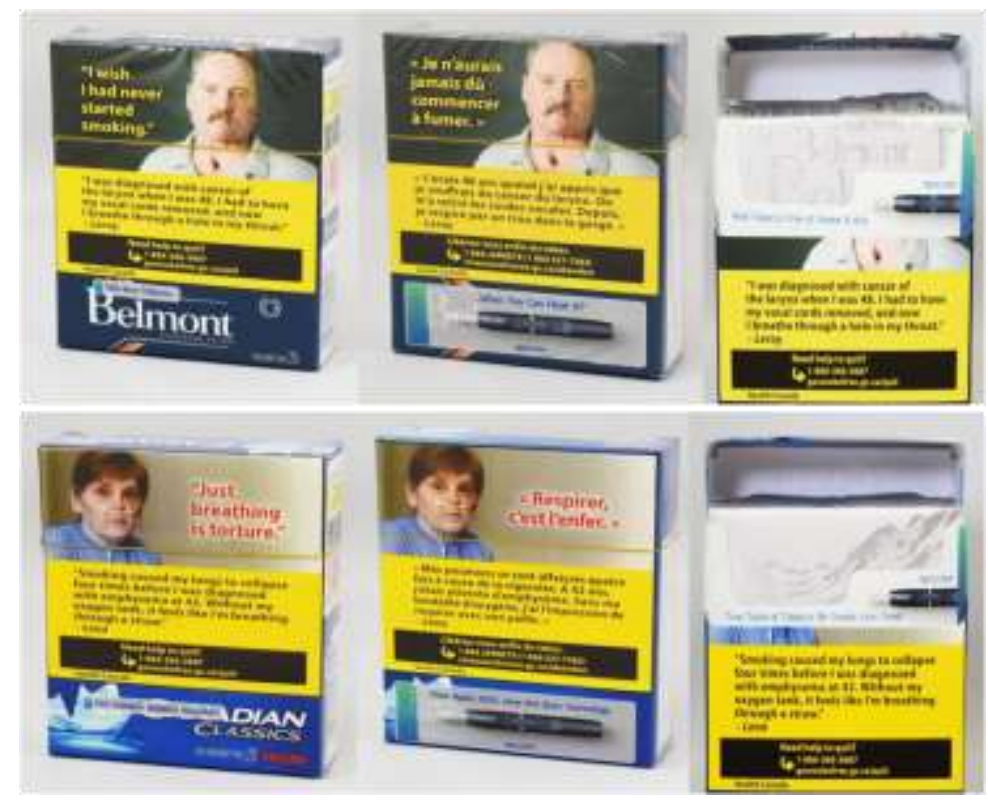

Irrespective of PMI's true intent with their New Year's resolution, their support for the inclusion of pack inserts promoting cessation may be a late Christmas present for public health. It is puzzling that in 17 years no country has followed the lead of Canada by requiring tobacco companies to include inserts aimed at promoting cessation in cigarette packs, while approximately 100 countries followed their lead by requiring pictorial health warnings on cigarette packs. After all, the health communication literature suggests that the most effective way to change behaviour is to combine fear messages (as generally communicated by the onpack health warnings) alongside messages promoting self- and response-efficacy (as used on inserts in Canada). In addition, the nascent literature is supportive of pack inserts promoting cessation, ${ }^{11-14}$ as is Article 11 of the WHO FCTC. ${ }^{15}$ There are also no logistical challenges to their inclusion, given that tobacco companies have used pack inserts to promote their products across the world since the late 19 th century. ${ }^{16}$ With the largest global multinational tobacco company supportive of inserts promoting cessation, then so long as these are designed by public health what obstacles are in the way of regulators introducing this measure in the UK and elsewhere? 


\section{References}

1 Rahhal N. Philip Morris vows to give up smoking for the New Year: Tobacco giant plans to stop selling cigarettes as they turn to trendy vaping. Daily Mail Online, 3 January 2017. www.dailymail.co.uk/health/article-5233401/Philip-Morris-tryingcigarettes-2018.html (accessed 4 January 2018)

2 World Health Organisation. WHO Framework Convention on Tobacco Control. Geneva: World Health Organization; 2005.

3 UK Government. Standardised Packaging of Tobacco Products Regulations 2015; 2015. www.legislation.gov.uk/uksi/2015/829/pdfs/uksi_20150829_en.pdf (accessed 4 January 2018)

4 Euromonitor International. Passport: Cigarettes in the United Kingdom; 2017.

5 Scollo M, Zacher M, Coomber K, et al. Changes in use of types of tobacco products by pack sizes and price segments, prices paid and consumption following the introduction of plain packaging in Australia. Tob Control 2015;24:ii66-75.

$6 \quad$ Kidwell H. DIY attracts diversity. Tob J Intern 2016;5:109-11.

7 Department of Health. Towards a smokefree generation: Tobacco control plan for England; 2017. 
www.gov.uk/government/uploads/system/uploads/attachment_data/file/630217/Towa

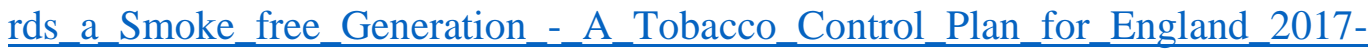

2022 2_.pdf (accessed 6 January 2018)

8 Chapman S. Tobacco giant wants to eliminate smoking . . Br Med J 2017;358.

9 Dewhirst T. Into the black: Marlboro brand architecture, packaging and marketing communication of relative harm. Tob Control, in press.

10 Smoking and Health Action Foundation/ Non-Smokers' Rights Association.

Backgrounder on the Canadian Tobacco Market; 2013. https://nsra-adnf.ca/wp-

content/uploads/2016/08/2013_Canadian_Tobacco_Market.pdf (accessed 4 January

2018)

11 Thrasher JT, Osman A, Abad EN, et al. The innovative use of cigarette package inserts to supplement pictorial health warnings: An evaluation of the Canadian policy. Nicot Tob Res 2015;17:870-5.

12 Thrasher JF, Swayampakala K, Cummings KM, et al. Cigarette package inserts can promote efficacy beliefs and sustained smoking cessation attempts: A longitudinal assessment of an innovative policy in Canada. Prev Med 2016;88:59-65.

13 Moodie C. Adult smokers' perceptions of cigarette pack inserts promoting cessation: a focus group study. Tob Control 2018;27:72-7.

14 Mucan B, Moodie C. Young adult smokers' perceptions of plain packs, numbered packs and pack inserts in Turkey: A focus group study. Tob Control, in press.

15 World Health Organisation. Guidelines for implementation of Article 11 of the WHO Framework Convention on Tobacco Control; 2008. www.who.int/fctc/guidelines/article_11.pdf?ua=1 (accessed 15 January 2018)

16 Cross GS, Proctor RN. Packaged pleasures. How technology and marketing revolutionized desire. London: University of Chicago Press; 2014. 
